\title{
Halophilic polysulfabetaines - synthesis and study of gelation and thermoresponsive behavior $\dagger$
}

Cite this: RSC Adv., 2014, 4, 22596

\author{
Vivek Arjunan Vasantha, ${ }^{\text {*a }}$ Satyasankar Jana, ${ }^{a}$ Anbanandam Parthiban ${ }^{\star a}$ \\ and Julius G. Vancso ${ }^{\text {ab }}$
}

Received 1st February 2014

Accepted 12th May 2014

DOI: $10.1039 / c 4 r a 00928 b$

www.rsc.org/advances

Polysulfabetaines (PSBs) derived from zwitterionic sulfates (contrary to commonly used polysulfobetaines which are derived from zwitterionic sulfonates) were synthesized for the first time. PSBs dissolved in brine (halophilic), swelled in deionized water and also exhibited reversible and irreversible thermoresponsive behavior. Large differences in interaction with deionized water and brine solution as well as morphology of particles in dispersion was observed between poly[2(dimethyl(4-vinylbenzyl)ammonio)ethyl sulfate] (PSB 1) and poly[3(dimethyl(4-vinylbenzyl)ammonio)propyl sulfate] (PSB 2) even though a single methylene $\left(-\mathrm{CH}_{2}-\right)$ unit was the sole differentiating factor. The gelation and thermoresponsive behaviour observed in PSBs are similar to that of naturally occurring polymers.

Polymers bearing ionic groups such as polyampholytes and zwitterionic polymers have great potential for various applications due to their unique interactions in aqueous solutions. ${ }^{1-3}$ Polymeric zwitterionic sulfonates also known as polysulfobetaines $^{4-9}$ are the predominant class of zwitterionic polymers widely reported thus far because of ease of synthesis as well as due to the commercial availability of wide variety of starting materials. In the case of polysulfobetaines, property variations are introduced by way of either changing the number of methylene units between cationic species which is largely ammonium ion and the sulphur atom or by changing the nature of cation forming unit i.e. the tertiary amine or quarternizable amino compound. The former approach is limited in that the number of carbon atoms can only be varied between three and four. However, by changing the nature of cationic moiety, we recently introduced exceptional changes to the

${ }^{a}$ Institute of Chemical and Engineering Sciences (ICES), Agency for Science, Technology and Research (A*STAR), 1 Pesek Road, Jurong Island, Singapore 627833. E-mail: vivek_vasantha@ices.a-star.edu.sg; aparthiban@ices.a-star.edu.sg

${ }^{b} \mathrm{MESA}+$ Research Institute for Nanotechnology, Faculty of Science and Technology, University of Twente, P. O. Box 217, 7500 AE Enschede, The Netherlands

$\dagger$ Electronic supplementary information (ESI) available: Detailed experimental description and results including ${ }^{1} \mathrm{H}$ NMR, FT-IR DLS, TEM, detailed phase studies etc. See DOI: 10.1039/c4ra00928b nature of polymer in terms solubility and other characteristics. ${ }^{10}$ There are possibilities to further influence the characteristics of zwitterionic polymers. One such possibility is the zwitterionic polysulfates which can also be called as polysulfabetaines. Unlike the polysulfobetaines where sulphur atom of sulfonate group is directly linked to carbon, in polysulfabetaines, carbon atom is linked to sulphur through oxygen atom (Fig. 1). Theoretically, this additional oxygen atom can be expected to introduce more hydrophilicity to the polymer. The presence of additional heteroatom in the form of oxygen also increases the distance between counterions. Such increase in distance could ultimately influence the nature of ionic interactions. ${ }^{11}$ Under some circumstances, the interaction may become more of intermolecular in nature than intramolecular. ${ }^{12}$ As reported herein, this turned out to be true. Substantial difference in properties were observed even between two polymers where a single methylene $\left(-\mathrm{CH}_{2}-\right)$ unit was the sole distinguishing factor. Though there are many reports on the synthesis of polysulfobetaines, to the best of our knowledge reports on polysulfabetaines are non-existent. Polysulfabetaines exhibit many interesting characteristics as discussed hereunder including dissolution in concentrated sodium chloride solutions and thus the term halophilic ("salt-loving"). It may be noted that microorganisms like bacteria living under harsher conditions such as brine of varying concentration are commonly referred to as halophilic in literature. ${ }^{13-17}$ (a)

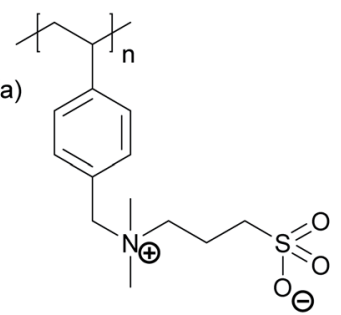

(b)

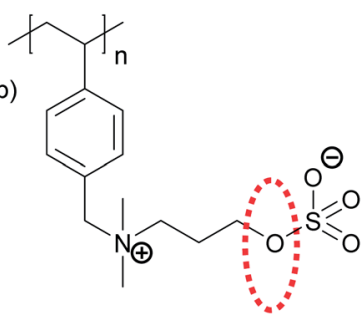

Fig. 1 Typical chemical structure of (a) polysulfobetaine and (b) polysulfabetaine. 
The polymerizable sulfabetaine monomers SBM 1 and 2 were prepared in a single step by ring opening reaction ${ }^{\mathbf{1 8}}$ of cyclic 1,2-ethylene sulfate and 1,3-propylene sulphate (Schemes 1 and $\mathrm{S} 1 \dagger$ ) by $N$-(4-vinylbenzyl)- $N, N$-dimethylamine, which led to zwitterionic sulfabetaine monomers in good yields (83-87\%). To the best of our knowledge, SBM 1 and 2 have not been reported before. SBM 1 and 2 were obtained as powders which were highly hygroscopic and were thoroughly characterized. The ${ }^{1} \mathrm{H}-\mathrm{NMR}$ spectrum of SBM 1 and 2 are given in Fig. 2. Table $\mathrm{S} 1 \dagger$ describes the melting point and mass spectroscopic characterization of sulfabetaine monomers SBM 1 and 2.

SBM 1 and 2 were polymerized by free radical polymerization using 4,4'-azobis(4-cyanovaleric acid) (ACVA) at $90{ }^{\circ} \mathrm{C}$ in $0.5 \mathrm{M}$ aqueous NaBr solution to yield polysulfabetaines, PSB 1 and 2 respectively. Scheme 1 also shows the polymerization of sulfabetaine monomers. PSB 1 and 2 were thoroughly characterized by spectroscopic techniques. The polymerization conditions are summarized in Table S2. $\dagger$ The complete disappearance of vinyl protons after polymerization can be noticed in Fig. 2 which displays the ${ }^{1} \mathrm{H}$-NMR spectra of PSB 1 and 2. PSB 1 and 2 were also characterized by FT-IR (Fig. S1 $\dagger$ ) and UV-Vis (Fig. S2 $\dagger$ ) spectroscopic techniques. The solubility characteristics of PSB 1 and 2 were determined in various solvents as detailed in Table S3. $\dagger$ PSB 1 and 2 were found to be soluble in formic acid, hexafluoroisopropanol, saturated $\mathrm{NaCl}$ solution, trichloroacetic acid and trifluoroethanol. Both PSB 1 and 2 were completely insoluble in common organic solvents like acetic acid, chloroform, methanol as well as in dipolar aprotic solvents like DMF, DMSO, etc.

The presence of directly linked heteroatoms in the from of $\mathrm{C}-\mathrm{O}-\mathrm{S}$ linkage in the case of polysulfabetaines warranted us to determine the hydrolytic stability of polysulfabetaines. Table 1 summarizes the hydrolytic stability of PSB 1 and 2. Polysulfabetaines were heated in deionized water and aqueous solution of $6 \mathrm{M} \mathrm{HCl}$ at $95{ }^{\circ} \mathrm{C}$ for $24 \mathrm{~h}$ in two separate reactions to evaluate hydrolytic stability. The sulphur content of the starting polymers and that of those subjected to hydrolysis were determined by elemental analysis. Since the $\mathrm{O}-\mathrm{S}$ linkage is expected to cleave upon hydrolysis, the polysulfabetaines undergoing hydrolysis would show lesser (partial hydrolysis) to no or near zero sulphur (substantial to complete hydrolysis) content. As can be noticed from Table 1, the extent of hydrolysis in

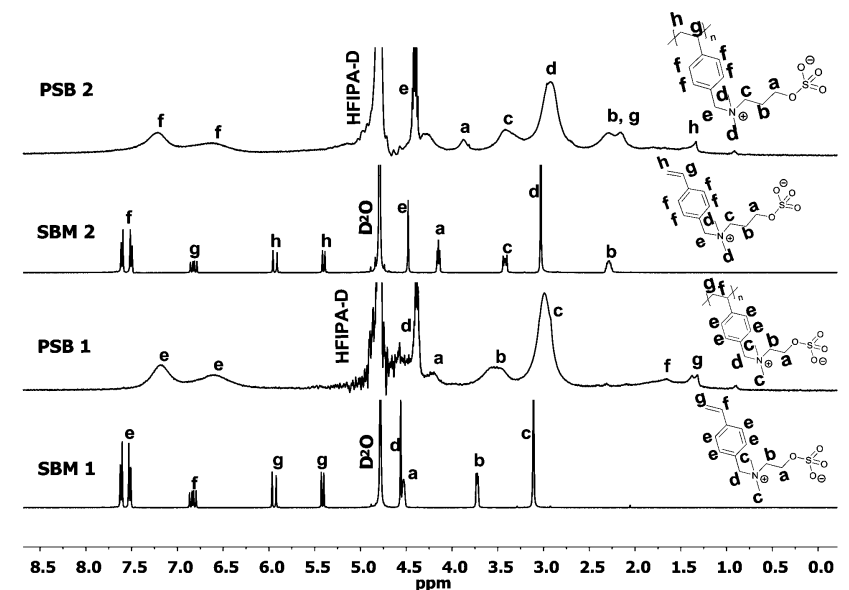

Fig. $2{ }^{1} \mathrm{H}$-NMR spectra of sulfabetaine monomers (SBM) in $\mathrm{D}_{2} \mathrm{O}$ and corresponding polysulfabetaines (PSB) in $\left(\mathrm{CF}_{3}\right)_{2}-\mathrm{CD}-\mathrm{OD}$.

deionized water was negligible. Even in $6 \mathrm{M} \mathrm{HCl}$ acid solution the extent of hydrolysis was about $60 \%$ thereby indicating that polysulfabetaines are fairly stable.

Polysulfabetaines, PSB 1 and 2 absorbed water to a varying degree and formed hydrogels. The swelling tendency and the lack of solubility in deionized water in spite of their zwitterionic character are due to strong ionic interactions. The equilibrium swelling and hydration studies of PSBs are summarized in Table 2. The water absorption of PSB 1 was found to be $0.95 \mathrm{~g}$ per $\mathrm{g}$ of polymer. PSB 2 absorbed significantly higher amount of water (1.97 $\mathrm{g}$ per $\mathrm{g}$ of polymer) (Table $\mathrm{S} 4 \dagger$ ). The difference in water absorbing tendency between PSB $\mathbf{1}$ and $\mathbf{2}$ is likely due to the

Table 1 Hydrolytic stability of polysulfabetaines

\begin{tabular}{lllll}
\hline Polymer & $\begin{array}{l}\text { Sulfur } \\
\text { content } \\
\text { (calc.) }\end{array}$ & $\begin{array}{l}\text { Sulfur } \\
\text { content } \\
\text { (observed) }\end{array}$ & $\begin{array}{l}\text { Sulfur content } \\
\text { after treatment } \\
\text { with DI water }\end{array}$ & $\begin{array}{l}\text { Sulfur content } \\
\text { after treatment } \\
\text { with 6 M HCl }\end{array}$ \\
\hline PSB 1 & 11.16 & 10.31 & 10.31 & 4.3 \\
PSB 2 & 10.64 & 10.2 & 9.92 & 4.01
\end{tabular}

${ }^{a}$ After heating at $95{ }^{\circ} \mathrm{C}$ for $24 \mathrm{~h}$. The polymers were dialyzed and lyophilized before elemental analysis.

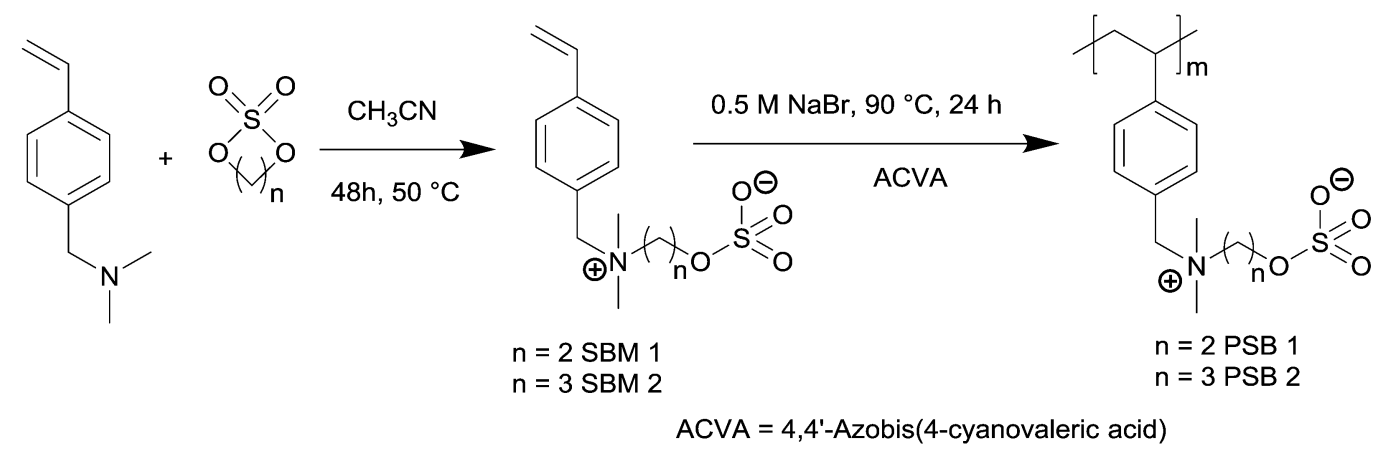

Scheme 1 Polymerization of zwitterionic sulfabetaine monomers. 
Table 2 Swelling, thermal and solubility characteristics of PSB 1 and 2

\begin{tabular}{|c|c|c|c|c|}
\hline \multirow[b]{2}{*}{ Sample } & \multirow{2}{*}{$\begin{array}{l}\text { Swelling } \\
\text { ratio }^{a} \text { (SR), } \\
\% \mathrm{DI} \mathrm{H}_{2} \mathrm{O}\end{array}$} & \multirow{2}{*}{$\begin{array}{l}\mathrm{DSC}^{b} \\
\left(T_{\max },{ }^{\circ} \mathrm{C}\right)\end{array}$} & \multicolumn{2}{|c|}{$\begin{array}{l}\text { Critical salt concentration }{ }^{c} \\
(\mathrm{CSC}, \mathrm{wt} \%)\end{array}$} \\
\hline & & & Titration & Transmittan \\
\hline PSB 1 & $95.08 \pm 4.8$ & 58 & $\begin{array}{l}21.04 \pm 0.2 \\
(3.59 \mathrm{M})\end{array}$ & 21.71 \\
\hline PSB 2 & $197.86 \pm 6.7$ & 72 & $\begin{array}{l}12.93 \pm 0.2 \\
(2.21 \mathrm{M})\end{array}$ & 12.09 \\
\hline
\end{tabular}

${ }^{a} \mathrm{SR}=[($ weight of swollen polymer - weight of dry polymer $) /$ weight of dry polymer] $\times 100 .{ }^{b}$ Endothermic transition signifying the temperature at which expulsion of water from the swollen polymers occurred. ${ }^{c}$ For CSC, 1.11 wt $\%$ of PSB 1 and 0.87 wt $\%$ of PSB 2 were dissolved in $22.62 \mathrm{wt} \%$ of $\mathrm{NaCl}$ solution and titrated with deionised water at $25^{\circ} \mathrm{C}$ (Fig. S7 $\dagger$ ).

nature of interactions prevailing in the sulfabetaine polymers. The presence of extra methylene unit $\left(-\mathrm{CH}_{2}-\right)$ could aid in the flexibility as well as separate the charges farther apart. The former effect could help in creating larger ion cages which could accommodate more water. The latter could enhance the interchain interactions which can also create larger void thereby facilitating the binding of more water molecules. PSB 2 also showed increased absorption tendency in 0.9 wt $\%$ aqueous $\mathrm{NaCl}$ solution. In this case, the absorption was found to be $8 \mathrm{~g}$ per $g$ of polymer.

The hydrogel is formed by the polar interaction between zwitterions and water as well as by the presence of water in voids existing in the network formed through ionic interactions. Since heating the gel can disturb these interactions, the behavior of hydrogels was studied by differential scanning calorimetry (DSC) (Fig. S3†). In DSC analysis, PSB 1 hydrogel exhibited an endothermic transition centred around at $58{ }^{\circ} \mathrm{C}$, while PSB 2 showed an endothermic transition at $72{ }^{\circ} \mathrm{C}$. As was also visually observed and will be described later, heating helped the chains to align together closely which in turn enhanced the ionic interactions because of which association with water was disturbed. As a consequence, water was expelled from the network and also induced contrasting morphological changes in the precipitated polymer as observed in a transmission electron microscope (TEM).

In polysulfobetaines derived from methacrylate and acrylamide $^{\mathbf{1 9 - 2 3}}$ the network was gradually destroyed at higher temperature in water and became soluble (UCST). In contrast, PSB gels underwent temperature induced collapse and showed some unexpected morphological changes. Visually, the expulsion of water from PSB hydrogels, as indicated by the formation of deep milky appearance upon heating, occurred, in PSB 1 around $55-60{ }^{\circ} \mathrm{C}$ and in PSB 2 around $60-65{ }^{\circ} \mathrm{C}$ which are comparable to the transitions observed in DSC. The polymers began to coagulate and precipitate, when the gel was kept for very short time $(<1 \mathrm{~min})$ above the cloud point temperature (Fig. 3b). This phenomenon is comparable to the situation prevailing in some biomacromolecules. It is well known that upon thermal treatment biomacromolecules such as gelatin, polysaccharides, collagen and lactoglobulin undergo

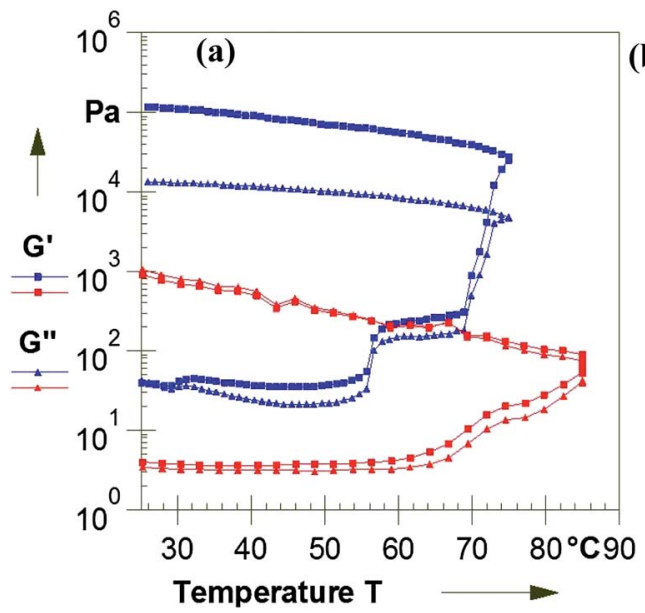

(b)

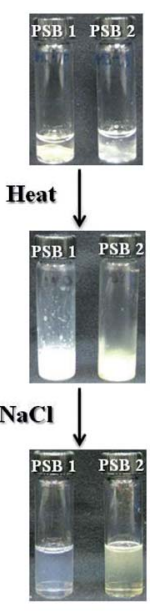

Fig. 3 Irreversible thermoresponsive behaviour of polysulfabetaine by temperature sweep oscillatory measurement at a constant frequency of $1 \mathrm{~Hz}$ and constant strain of $1 \%$ in a heating and cooling process PSB 1 (51 wt\%) and : PSB 2 (17.69 wt\%) (a). Photograph of hydrogel before and after heat treatment in presence of DI water and dissolution upon addition of salts (b).

conformational changes, resulting in the formation of network structures through strong intermolecular interactions. ${ }^{\mathbf{1 2 , 2 4 , 2 5}}$

The rheological properties of PSB hydrogels were studied by time, amplitude and frequency sweep measurements (Fig. S4 $\dagger$ ). Frequency sweep measurements of PSB hydrogels showed that the storage modulus ( $G^{\prime}$, the elastic response) and the loss modulus $\left(G^{\prime \prime}\right.$, the viscous response) were dependent over the entire frequency range. The data suggested that the measured $G^{\prime}$ exhibited characteristic linear viscoelastic behaviour. However, large variations observed in the curve clearly indicate the difference in nature of interaction between PSB 1 and 2 . The result reflected the gel-like behaviour of PSB 1 and 2 and there was no break-up of the gel microstructure.

The irreversible changes that occurred in PSB hydrogels upon heating due to the enhanced ionic interactions between the charged sulfate, and ammonio groups were also evidenced by temperature dependent oscillatory measurement and were consistent with the phase transitions observed visually as well as by DSC. Fig. 3a shows that upon increasing the temperature from 25 to $55{ }^{\circ} \mathrm{C}$, a slight increase of $G^{\prime}$ was observed. Above $55^{\circ} \mathrm{C}, G^{\prime}$ started to increase with temperature indicating that gel network was broken which can be attributed to the expulsion of water. Above $60-75{ }^{\circ} \mathrm{C}$ represented the temperature range where $G^{\prime}$ modulus increased abruptly upon heating because of the formation of self assembled 3D networks (Fig. 3) of varying dimension and shape as dictated by the nature of basic ionic interactions. Upon increasing the temperature above phase transition, higher values of $G^{\prime}$ were reached, indicating the formation of a more stable, irreversible network. Also, the increase in $G^{\prime}$ and $G^{\prime \prime}$ after phase transition indicated the existence of a stiffened network. Upon cooling, $G$ and $G^{\prime \prime}$ showed some deviation thereby showing the irreversible behaviour.

The self-assembly ${ }^{26,27}$ of heat-induced aggregates of PSB was investigated by TEM and dynamic light scattering (DLS) 

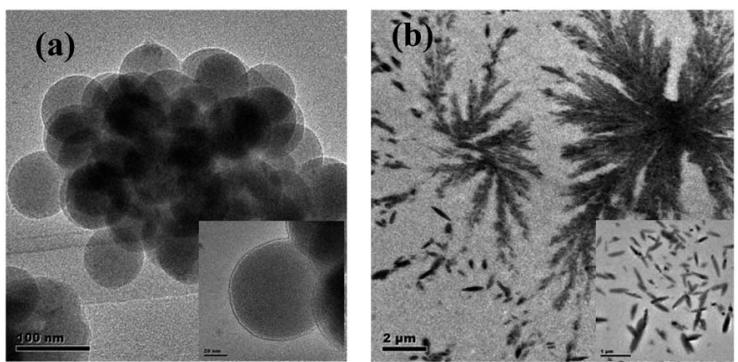

Fig. 4 TEM micrographs of PSB gel after heat treatment in the presence of water at $70^{\circ} \mathrm{C}$ for $15 \mathrm{~min}$ (a) spherical aggregates (PSB 1; scale bar: $100 \mathrm{~nm}$ and inset $20 \mathrm{~nm}$ ) and rod-like aggregates (PSB 2; scale bar: $2 \mu \mathrm{m}$ and inset $1 \mu \mathrm{m})$.

techniques. Fig. 4a and b show TEM images of the PSB gels $\left(1 \mathrm{wt} \%\right.$ ) after heat treatment at $70{ }^{\circ} \mathrm{C}$ for $15 \mathrm{~min}$. It is clear from TEM micrographs that PSBs formed self-assembled aggregates. At $70{ }^{\circ} \mathrm{C}$, PSB 1 formed spherical, predominantly monodispersed aggregates in the range of 70-90 nm (Fig. S5†). The shape of the aggregates obtained for PSB 2, on the other hand, was completely different, rod like aggregates of 300-600 nm with the cross-section of around $100 \mathrm{~nm}$. PSB 2 formed large macro aggregates predominantly through interchain interactions which prolonged to the extent of forming fibrils ${ }^{28}$ similar to irreversible hydrocolloids like collagens ${ }^{25,29}$ or carrageen. ${ }^{30}$ Interestingly, the dendritic micellar microstructures observed in PSB 2 was caused by the presence of one additional methylene unit as compared to PSB 1.

DLS experiments further validated these observations (Fig. S6 $\dagger$ ). Upon addition of salt to the heat treated dispersions, deep milkiness of the dispersion changed to more translucent in appearance thereby indicating that solvation of zwitterions accompanied by the uncoiling of chains under the influence of charged interaction of the added electrolyte (Fig. 3b). PSB polymer chains folded at higher temperatures due to the prevalence of intra- and interchain ionic interactions and near complete unfolding occurred upon the addition of salt thus showing unusual halophilic behaviour.

The halophilic polysulfabetaines, PSB 1 and 2 also exhibited temperature dependent phase separation in brine solution. The characteristically different states were observed at low (turbid phase; association) and high temperatures (clear phase; dissociation). This association-dissociation behaviour depended on the critical salt concentration ${ }^{31-33}$ (CSC) or critical electrolyte concentration $^{34}$ (CEC) (minimum salinity that can cause dissolution) and is summarized in Table 2 (Fig. S7†). Like polysulfobetaines, ${ }^{10,35-37}$ polysulfabetaines also exhibited reversible UCST behavior in salt solution between $20{ }^{\circ} \mathrm{C}$ and $97{ }^{\circ} \mathrm{C}$. This phase transition represents, to the best of our knowledge, the first example of a thermoresponsive UCST behavior in presence of higher salt concentration. As expected, with decrease in salt concentration the UCST increased. The three dimensional plot of the UCST of the PSBs as a function of $\mathrm{NaCl}$ and polymer concentrations with respect to temperature is shown in Fig. 5a. As can be inferred from Fig. 5a, the UCST window shifted from low temperature region to high temperature region, simply

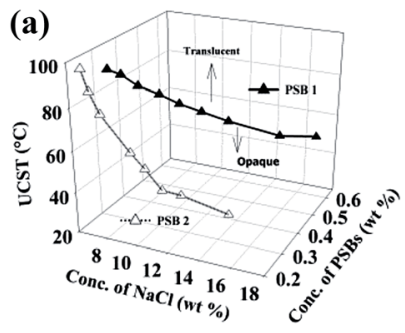

(b)

Fig. 5 Reversible UCST behavior by association and dissociation of PSBs with respect to salt concentration after increasing the temperature from 20 to $97^{\circ} \mathrm{C}$; (a) the filled and open symbols represents the phase boundaries of the PSB 1 and 2 in $\mathrm{NaCl}$ respectively. (b) Photographs of PSBs in $\mathrm{NaCl}$ solution before and after heat treatment; PSB 1 (1.03 wt\% of PSB 1 in 21.04 wt\% $\mathrm{NaCl}$ ) and PSB 2 (0.49 wt\% of PSB 2 in $12.93 \mathrm{wt} \% \mathrm{NaCl})$.

upon lowering the salt concentration (Fig. S8†). UCST of PSB 1 was higher than that of PSB 2. Furthermore, it was observed that PSB 2 favoured less interaction when compared to its counterpart thereby indicating the prevalence of interchain interactions caused by the additional methylene unit. It may be noted that similar trend was observed in sulphate based low molecular weight surfactants as well..$^{38,39}$

The reversibility of turbid-to-clear (globular-to-coil conformations) transitions in brine solution upon increasing the temperature was further studied using DLS (Fig. S9†) and viscometry. At the elevated temperature, above the UCST, the PSBs became clear without any observable aggregates (coil form; 25-60 nm) due to charge screening (better solvation thus greater solvent-polymer interaction and reduced polymerpolymer interaction). As the temperature decreased, the polymer conformation changed, resulting in the collapse of the polymer coil which led to larger aggregates (like globular) with the average size above $400 \mathrm{~nm}$ (greater polymer-polymer interaction). This resulted in the formation of turbid solution. Heating induces dissociation caused by the mobility of polymer chains. Additionally, the tendency to form aggregates below UCST was also supported by viscosity studies (Fig. S10†). Similar to polysulfobetaines, ${ }^{\mathbf{1 0}}$ polysulfabetaines also showed nonNewtonian behaviour (Fig. S11†), due to the enhanced chainchain interactions caused by zwitterionic nature at higher shear rate. Thus, polysulfabetaines exhibited electrolyte induced thermoresponsive behaviour which is accompanied by conformational changes such as globule-to-coil transition.

In summary, we have reported a novel class of halophilic, thermoresponsive polysulfabetaines. The presence of one extra methylene unit between the counterions of polysulfabetaines induced more interchain interactions thereby influenced properties like water uptake, sorption of brine solution, contrasting rheological and thermoresponsive behaviour. Ionic interactions increased with temperature which resulted in the expulsion of water from swollen polysulfabetaine gels. The nature of interactions (intra- vs. inter-) also determined the shape of particles formed which varied from spherical to rod like, dendritic aggregates. Furthermore, polysulfabetaines showed a characteristic and reproducible thermoresponsive 
behavior in salt solution. UCST behaviour was influenced by the concentration of salt as well as temperature. Such a subtle behavior of polysulfabetaines in brine solution is very interesting and may be suited for a range of applications such as enhanced oil recovery in the petroleum field and low temperature precipitation of proteins in biomedical field.

\section{Acknowledgements}

This work was funded by the Agency for Science, Technology and Research (A*STAR), Singapore under Innovative Marine Antifouling Solutions (IMAS) for high-value applications programme. The authors thank Ms. Chen Junhui and Ms. Foo Ming Choo for assisting in GPC and DLS studies and Ms. Tay Boon Ying for assistance with TEM analysis.

\section{Notes and references}

1 A. V. Dobrynin, R. H. Colby and M. Rubinstein, J. Polym. Sci., Part B: Polym. Phys., 2004, 42, 3513-3538.

2 S. E. Kudaibergenov and A. Ciferri, Macromol. Rapid Commun., 2007, 28, 1969-1986.

3 S. Jana, V. A. Vasantha, L. P. Stubbs, A. Parthiban and J. G. Vancso, J. Polym. Sci., Part A: Polym. Chem., 2013, 51, 3260-3273.

4 A. B. Lowe and C. L. McCormick, Chem. Rev., 2002, 102, 4177-4189.

5 M. S. Donovan, A. B. Lowe, T. A. Sanford and C. L. McCormick, J. Polym. Sci., Part A: Polym. Chem., 2003, 41, 1262-1281.

6 F. Q. Xuan and J. S. Liu, Polym. Int., 2009, 58, 1350-1361.

7 S. Y. Jiang and Z. Q. Cao, Adv. Mater., 2010, 22, 920-932.

8 J. Kuang and P. B. Messersmith, Langmuir, 2012, 28, 72587266.

9 Z. Cao and S. Jiang, Nano Today, 2012, 7, 404-413.

10 V. A. Vasantha, S. Jana, A. Parthiban and J. G. Vancso, Chem. Commun., 2014, 50, 46-48.

11 R. G. Laughlin, Langmuir, 1991, 7, 842-847.

12 B. Ozbas, J. Kretsinger, K. Rajagopal, J. P. Schneider and D. J. Pochan, Macromolecules, 2004, 37, 7331-7337.

13 B. van den Burg, Curr. Opin. Microbiol., 2003, 6, 213-218.

14 P. DasSarma, J. A. Coker, V. Huse, S. DasSarma and M. C. Flickinger, in Encyclopedia of Industrial Biotechnology, John Wiley \& Sons, Inc., 2009.

15 A. Oren, Microbiol. Mol. Biol. Rev., 1999, 63, 334-348.

16 J. M. Pastor, M. Salvador, M. Argandona, V. Bernal, M. ReinaBueno, L. N. Csonka, J. L. Iborra, C. Vargas, J. J. Nieto and M. Canovas, Biotechnol. Adv., 2010, 28, 782-801.
17 A. Oren, Environ. Technol., 2010, 31, 825-834.

18 D. A. Tomalia and J. C. Falk, J. Heterocycl. Chem., 1972, 9, 891-894.

19 J. C. Salamone, W. Volksen, A. P. Olson and S. C. Israel, Polymer, 1978, 19, 1157-1162.

20 S. Liang, Q. M. Yu, H. Yin, Z. L. Wu, T. Kurokawa and J. P. Gong, Chem. Commun., 2009, 7518-7520.

21 J. C. Galin and M. Galin, J. Polym. Sci., Part B: Polym. Phys., 1995, 33, 2033-2043.

22 J. Ning, G. Li and K. Haraguchi, Macromolecules, 2013, 46, 5317-5328.

23 Z. Zhang, T. Chao and S. Jiang, J. Phys. Chem. B, 2008, 112, 5327-5332.

24 M. Meyer, M. Antonietti and H. Schlaad, Soft Matter, 2007, 3, 430-431.

25 H. Hoermann and H. Schlebusch, Biochemistry, 1971, 10, 932-937.

26 T. Vermonden, R. Censi and W. E. Hennink, Chem. Rev., 2012, 112, 2853-2888.

27 P. J. Roth, T. P. Davis and A. B. Lowe, Polym. Chem., 2012, 3, 2228-2235.

28 V. J. Bradford and B. L. Iverson, J. Am. Chem. Soc., 2008, 130, 1517-1524.

29 K. E. Kadler, D. F. Holmes, J. A. Trotter and J. A. Chapman, Biochem. J., 1996, 316, 1-11.

30 T. Funami, M. Hiroe, S. Noda, I. Asai, S. Ikeda and K. Nishimari, Food Hydrocolloids, 2007, 21, 617-629.

31 V. M. Monroy Soto and J. C. Galin, Polymer, 1984, 25, 254262.

32 D. A. Z. Wever, F. Picchioni and A. A. Broekhuis, Prog. Polym. Sci., 2011, 36, 1558-1628.

33 K. C. Khilar and H. S. Fogler, J. Colloid Interface Sci., 1984, 101, 214-224.

34 E. E. L. Kathmann, L. A. White and C. L. McCormick, Macromolecules, 1997, 30, 5297-5304.

35 D. N. Schulz, D. G. Peiffer, P. K. Agarwal, J. Larabee, J. J. Kaladas, L. Soni, B. Handwerker and R. T. Garner, Polymer, 1986, 27, 1734-1742.

36 J. Seuring and S. Agarwal, Macromol. Rapid Commun., 2012, 33, 1898-1920.

37 Q. Zhang, J.-D. Hong and R. Hoogenboom, Polym. Chem., 2013, 4, 4322-4325.

38 P. G. Faulkner, A. J. I. Ward and D. W. Osborne, Langmuir, 1989, 5, 924-926.

39 P. G. Nilsson, B. Lindman and R. G. Laughlin, J. Phys. Chem., 1984, 88, 6357-6362. 